\title{
Research on Image Perception of Heritage Destination Based on Web Text Analysis : Taking Hongcun Village as an Example
}

\author{
Jingjing Wang ${ }^{1}$, Yanling Huang ${ }^{1, *}$, Shengfeng Luo ${ }^{1}$,Shulin Xiao ${ }^{1}$ \\ ${ }^{1}$ College of Tourism \& Landscape Architecture, Guilin University of Technology, Guilin, China.
}

\begin{abstract}
This paper focuses on Hongcun in Anhui Province, using comments data of ctrip.com, ly.com and qunar.com as a samples, and makes a systematic analysis of Hongcun's tourism image through Python software. The study finds that the dimension of Hongcun image perception includes tourism attraction, tourism service, tourism environment and tourism atmosphere. The perception curve of tourism images of Hongcun presents the distribution characteristics of power functions, with obvious "long tail" distribution.Tourists have higher evaluation of Natural scenery and historical features, and lower evaluation for over-commercialization,single tourism items and disordered management in tourism-peak season. Accordingly, it is necessary to establish the concept of protective development and protect the authenticity of Hongcun . At the same time, it is necessary to enrich the cultural connotation of tourism products and enhance the experience of tourists.
\end{abstract}

\section{Introduction}

Heritage tourism is not only an important part of tourism, but also an important field of tourism research.Heritage tourism is a form of tourism that is the main attraction of cultural relics and historical civilizations such as cultural relics and historic sites.In recent years, with the rise of integration of culture and tourism, research on the protection and development of cultural heritage tourism has become increasingly rich, and cultural heritage tourism destinations have become important tourist attractions.Experiencing the culture of heritage sites has become one of the motives for tourists to travel. Tourists' perception of heritage tourism plays a crucial role in making tourism decisions [1]. As a typical representative of ancient villages in China, Hongcun was listed in the world heritage list by UNESCO World Heritage Committee in 2000.

In recent years, the research on the image of tourist destination has increased dramatically. Tourists' cognition of the destination image is influenced by the overall impression of the destination, but the composition of the overall impression of the destination mainly includes two views [2-3]. Echtner (1991) proposed the three-dimensional space method, which divides the whole image of the destination into the whole and the individual components [4]. Baloglu (1999) proposed a mental schema method based on the tourists' perception of time series, which divides the tourists' perception image of tourist destination into cognitive image, emotional image and overall image [5]. In the study of tourists' perception, psychological mental schema has been widely used. For example, the image perception research of different types of tourist destinations, the comparative study of tourist perception image and official publicity image, etc [6-7].

With the development of the Internet, a large number of online texts are influencing tourists' perception of destination image and the formation of final tourism intention.Through reading relevant literatures, it is found that most scholars choose to use content analysis method to study tourism destinations, and it has become a new research trend to study tourism destination image perception by using online texts. However, there are few studies on the image perception of cultural heritage tourism destinations in the middle of China, and there is also a lack of relevant cases in the study of heritage tourism destinations under the network text. Therefore, This study takes the online reviews of tourists as a sample, and explores the tourists' image perception of Hongcun through content analysis, in order to provide reference for the sustainable development of Hongcun.

\section{Research design}

In the coming era of big data, a large number of information is emerging through the network. The network text analysis method can transform the qualitative data into quantitative data, which makes up for the low accuracy of the questionnaire survey method [8]. Therefore, this study uses the Jieba database and snowlp database of Python software to process highfrequency words and judge emotion of network data. In addition, through SPSS software, curve estimation analysis and parameter estimation are carried out .

This study selects comments from ctrip.com, ly.com and qunar.com as a sample. Due to the large number of selected reviews, the evaluation of tourists published

\footnotetext{
* Corresponding author: huangyanlinglucy@sina.com
} 
from January 1, 2018 to December 31, 2018 is captured through GooSeeker. In order to maximize the validity of the sample, the reviews selected in this study is preprocessed.This includes eliminating duplicate comments; removing invalid comments, including English letters, emoticons, etc.; correcting incorrect statements. Finally, 3662 valid comments were obtained.

\section{Data analysis}

\subsection{Cognitive dimension analysis}

The high-frequency characteristic words describing Hongcun's tourism image are extracted from Python's Jiaba database, and the high-frequency words irrelevant to tourism image perception and meaning repetition are filtered out. The top 50 words are selected for analysis.According to the existing cognitive image classification, tourists' perception of Hongcun's attributes includes four dimensions and seven subcategories, as shown in Table 1.

Table 1. Tourist cognition dimension table.

\begin{tabular}{|c|c|c|}
\hline Dimensions & Subcategories & $\begin{array}{c}\text { Characteristic words } \\
\text { (word frequency) }\end{array}$ \\
\hline \multirow[t]{2}{*}{$\begin{array}{l}\text { Tourism } \\
\text { attraction } \\
(36 \%)\end{array}$} & $\begin{array}{l}\text { Landscape } \\
\text { attraction }\end{array}$ & $\begin{array}{l}\text { architecture (766), scenic } \\
\text { spot (687),Hui Style } \\
\text { (535),scenery } \\
(432) \text {,Nanhu } \\
(423) \text {,landscape } \\
(404) \text {,hamlet } \\
\text { (404), ancient town } \\
\text { (158), Ink painting } \\
\text { (139),Crouching Tiger, } \\
\text { Hidden Dragon (110) }\end{array}$ \\
\hline & $\begin{array}{l}\text { Tourism } \\
\text { activities }\end{array}$ & $\begin{array}{l}\text { sketch（320）,Tour- } \\
\text { Guiding } \\
(132) \text {,photograph } \\
(130) \text {,sightseeing } \\
(124)\end{array}$ \\
\hline \multirow[t]{2}{*}{$\begin{array}{l}\text { Tourism } \\
\text { service } \\
(20 \%)\end{array}$} & $\begin{array}{l}\text { Dining and } \\
\text { Housing }\end{array}$ & $\begin{array}{l}\text { Inn (200), dwelling } \\
(150) \text {,online } \\
(92) \text {,accommodation } \\
(87) \text {,landlord(68) }\end{array}$ \\
\hline & $\begin{array}{l}\text { Scenic spot } \\
\text { management }\end{array}$ & $\begin{array}{l}\text { ticket }(565) \text {,free } \\
(115) \text {,ID card } \\
(123) \text {,cheap } \\
(87) \text {,administration } \\
(72)\end{array}$ \\
\hline $\begin{array}{l}\text { Tourism } \\
\text { environment } \\
(28 \%)\end{array}$ & $\begin{array}{c}\text { Natural } \\
\text { environment }\end{array}$ & $\begin{array}{l}\text { Huangshan city } \\
\text { (311),Huizhou } \\
\text { (226), night } \\
\text { (180),village } \\
\text { (175),Anhui ( } 83 \text { ), ,early } \\
\text { morning (91),reflection } \\
\text { (90), Yixian County } \\
\text { (84) ), morning } \\
\text { (72),Jiangnan }\end{array}$ \\
\hline
\end{tabular}

\begin{tabular}{|c|c|c|}
\hline & & (72),China(69) \\
\hline & $\begin{array}{l}\text { Humanities } \\
\text { environment }\end{array}$ & $\begin{array}{l}\text { culture }(265) \text {,guide } \\
(246) \text {,students } \\
(217) \text {,tourists } \\
(202) \text {,history } \\
(184) \text {,preserve } \\
(115) \text {,heritage (69) }\end{array}$ \\
\hline $\begin{array}{c}\text { Tourism } \\
\text { atmosphere } \\
(16 \%)\end{array}$ & Evaluation & $\begin{array}{l}\text { worthy }(282) \text {, distinctive } \\
(232) \text {,convenient } \\
(220) \text {,commercialization } \\
(179) \text {,beautiful (136), } \\
\text { typical (110),small } \\
(109) \text {, quiet (108) }\end{array}$ \\
\hline
\end{tabular}

The part of speech of high frequency words has certain meaning, in which the noun words can reflect the place and preference, the adjective words can express the attitude and perception, and the verb words can indicate the motivation and behavior.From the high-frequency noun words, we can see that the focus of tourists' attention includes tourist attractions, scenic tickets, accommodation, experience and other aspects, mainly concentrated in the cultural tourist attractions and natural landscape, of which the cultural tourist attractions account for the vast majority.It can be seen that tourists' perception of the overall image of Hongcun is a tourist destination of human landscape. The verb high frequency words include "sketch, photograph, sightsee and preserve", which reflect the behavior and motivation of tourists.High frequency adjectives include "Hui style, convenience, commercialization and beauty", which reflect tourists' perception of the overall landscape of Hongcun.

According to the cognitive dimension attribute, the high frequency words are sorted and analyzed.First, tourism attractions include tourism activities and landscape attractions, and the perception of landscape attractions is much higher than tourism activities. The highest frequency of words "architecture" reflects that tourists have a strong sense of Hongcun's architecture. The natural scenery like ink painting is most appreciated by tourists.Huizhou architecture and charming scenery are not only the most important tourism resources of Hongcun, but also the symbol of Hongcun.And in tourism activities, tourists have a higher perception of sketching and photographing, through which tourists can improve their experience in the scenic spot. From the perspective of tourism attractions, tourists mainly perform traditional sightseeing tours in Hongcun, lacking entertainment experience activities.

Second, tourists have a weak perception of tourism facilities services. Tourists have a higher perception of inns and dwellings and a lower perception of diet and transportation.This is mainly because Hongcun has a large number of well-preserved ancient dwellings of Ming and Qing dynasties, and most tourists are willing to experience local customs and experience the hospitality and service of the host. In terms of scenic spot management, it should be mentioned that the first term is "ticket", indicating that tourists are still very sensitive to scenic spot tickets. 
Third,tourism environment is the most profound part of tourists' perception. Combined with the online reviews and the high-frequency words "evening" and "early morning", most tourists feel the best experience of Hongcun in these two periods. The frequency of "guide" is higher, indicating that tourists are more concerned about the behavior of tour guides in the scenic spots [9]. In addition, from the perspective of Hongcun's own conditions, it is a sketch destination that art students like, so the rating of "student" is high.

Fourthly,tourists have a positive perception of the overall image of Hongcun. The high-frequency adjectives include "worth visiting, beautiful, convenient, commercialized and beautiful", which reflect the tourists' perception of the overall landscape of Hongcun. In addition to the word "commercialized", the words used by tourists to describe Hongcun are all positive, indicating that tourists have obtained high-quality tourism experience in the scenic spot.

\subsection{The long tail analysis of image perception}

According to long tail theory, as long as there are enough storage and circulation channels, the total market share of products with weak demand or poor sales volume can match the market share of a few hot-selling products [10]. In the network age, it is possible for people to pay attention to the "tail" with very low cost and bring unexpected benefits. Therefore, this study focused on the niche "tail" that affects tourists' perception and experience, selected the top 200 highfrequency words, used the serial number and frequency as variables for curve fitting, and determined the fitting model as a power function according to the goodness of fit, $Y=1494.734 .028 X^{-0.733}$. It can be seen from Figure 1 that the Hongcun tourism image perception curve shows an obvious long tail distribution. Therefore, in the practice of improving the tourism image of hongcun village, we should not only pay attention to the problems that are more popular with tourists, but also pay attention to the cognitive marginal areas of tourists.

Combined with the analysis of high-frequency words, it is found that the characteristic words in the head mainly reflect the hardware conditions of Hongcun, such as tourism landscape, accommodation and food. The feature words in the tail of concentration include the influencing factors of tourism satisfaction and the driving factors of tourists' decision-making, which are easy to be ignored in the research [11]. Therefore, while improving the hardware facilities of Hongcun tourism, we should pay more attention to the quality of tourism services, improve the experience of tourism services, and improve the soft power of Hongcun.

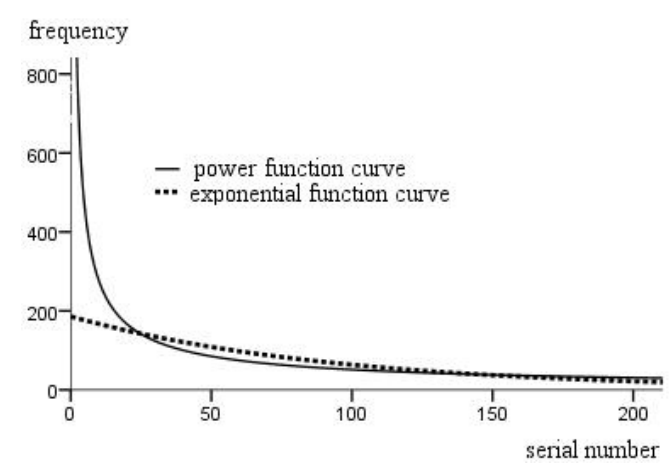

Fig. 1. Long tail distribution of tourism image perception.

\subsection{Emotional image}

Tourists' emotion has an important influence on loyalty and revisit willingness. Positive emotion of tourists will lead to higher loyalty and revisiting rate of tourists.Online reviews are short texts, often with strong personal feelings.Positive emotion of tourists will lead to higher loyalty and revisiting rate of tourists.Python's SnowNLP database is used to process Chinese text content, which can be used for word segmentation, text classification, emotional analysis, etc.. By reading each comment, the corresponding score of $0-1$ is generated. The higher the score is, the more positive the emotional polarity is, the value is biased to both sides, and the more extreme the emotion is.

It can be seen from Figure 2 that tourists' online reviews on Hongcun have obvious emotional characteristics.Positive and negative reviews account for a relatively high proportion, but the number of positive comments is far more than negative reviews. The results of emotional analysis show that the majority of tourists' experience in Hongcun is positive and the comments are polarized.The results of affective analysis correspond to the results of high frequency word analysis, but the negative affective components cannot be ignored. Tourists' positive perception of Hongcun comes from the overall impression and recognition of Huizhou culture, while their negative perception mainly comes from the commercialization of tourism development and the crowding of scenic spots in peak season.

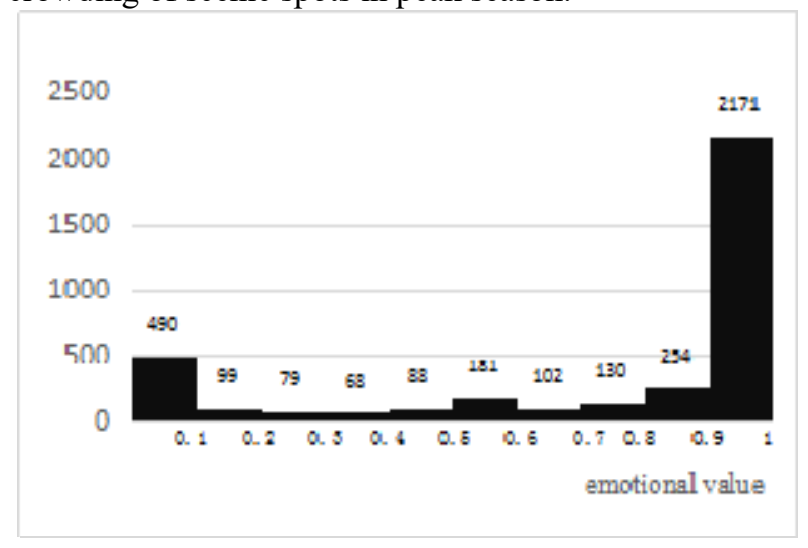

Fig. 2. Tourist's polarity of emotion. 


\section{Conclusions and suggestions}

\subsection{Conclusions}

Through the above analysis, tourists' perception of Hongcun's tourism image is summarized as follows:High frequency words such as "architecture, village, Huizhou" indicate that tourists' overall image perception of Hongcun is a cultural landscape tourism destination.Tourists' image perception of Hongcun mainly focuses on four aspects: tourism attraction, tourism service, tourism environment and tourism atmosphere. Secondly, the proportion of tourists' tourism activities is seriously unbalanced. Basic activities such as food, accommodation and transportation are mentioned most often and are affirmed by most tourists. However, shopping, entertainment and other activities are weakly perceived by tourists, which indicates that tourists' tourism activities in Hongcun are still in the primary stage of sightseeing. Finally, tourists' overall impression and emotional attitude towards Hongcun tend to be positive, but a few tourists have negative feelings.

\subsection{Suggestions}

According to the research conclusion, this paper puts forward the following three improvement suggestions from the perspective of tourists' perception. First,the development of scenic spots is mainly based on protection. As a world cultural heritage site, most tourists come to Hongcun to look for the ancient Huizhou impression. The rising number of tourists is in contradiction with the limited carrying capacity of the scenic spot [12]. The development of new scenic spots or facilities in the scenic area is bound to destroy its original characteristics, which runs counter to the publicity image of Hongcun. Therefore, in the development of tourism in Cultural Heritage Destinations, we should adhere to the principle of protection first, and try to maintain the original appearance of the scenic spot.

Second, the management of scenic spots should be strengthened. Online reviews reflect tourists' dissatisfaction with the management of scenic spots and over-commercialization. Therefore, the scenic spot should strengthen the standardization management construction, enhances the tourism service level.For example, the management department of Hongcun can set the maximum number of tourists per hour to guide tourists to visit in an orderly manner.

Last but not least, explore the cultural connotation of tourism products and improve the experience of tourists. Most tourists have a single activity type in the scenic spot, lacking experience.As for the unbalanced distribution of tourist activities in Hongcun scenic area, the publicity and development work should be done well in Hongcun scenic area,enrich tourists' tourism activities and improve tourists' satisfaction. At the same time, the scenic spots should increase the development of souvenirs with high cultural added value, realize the development mode of "culture + tourism", and make up for the shortage of single commodities in scenic spots.

\section{Acknowledgments}

Thanks for the help of the fund: The National Science Foundation of China Funded Project: Investigation on the Pro-poor tourism Effects and Influencing Mechanism on Settlement Space Evolution in Southwest Minority Villages (No.41661031). The Research launch Fund of Guilin University of Technology: Study on the Risk of Return to the Rural-village of the Southwestern Ethnic Tourism in the Sustainable Livelihood (GUTQDJJ2006039). The Open Fund of the key Laboratory (Research Base) of college of Tourism and Landscape Architecture, Guilin University of Technology: The Research and Countermeasures of Financial Support in the Tourism-oriented Poverty-relief Development in Guangxi (MZLY06).

\section{References}

1. Lu Fu. Social Scientist, 4(2019)

2. Li Liu. Tourism Tribune, 28(2013)

3. Yuanhao Huang, Qifu Lai, Feifei Lin. Resource Development and Market, 34(2018)

4. Echtner C M, Ritchie J R B. Journal of Travel Research, 31(1993)

5. Baloglu S, Mccleary K W. Annals of Tourism Research, 26(1999)

6. Papadimitriou D, Kaplanidou K, Apostolopoulou A. Journal of Hospitality and Tourism Research, 42(2018)

7. Wenting Zhang,Peicong Luo. Journal of Fujian Normal University(Natural Science Edition), 33(2017)

8. Ping Li, Tian Chen, Fuyuan Wang, et al. Geographical Research, 36(2017)

9. Fucheng Liu, Aili Liu, Min Liu, et al. Architectural Journal, 31(2017)

10. Chris A. The long tail. Beijing (CITIC Press,2012)

11. Xiaodong Sun, Rongxin Ni. Geographical Research, 37(2018)

12. Yuangang Zhang, Xiangyang $\mathrm{Yu}$, Jingjing Chen, et al. Human Geography, 33(2018) 